\title{
Interactive comment on "A standardized database of Marine Isotopic Stage 5e sea-level proxies on tropical Pacific Islands" by Nadine Hallmann et al.
}

\section{Paul Blanchon \\ blanchons@gmail.com \\ Received and published: 9 December 2020}

First, looking at Table 1, Relative SL indicators, there are problems with the narrow indicative range of coral terraces inferred by Rovere et al 2016.

It is stated that coral reef 'terraces' develop between the mean low water and breaking depth. However this ignores the fact that in the open Pacific coralgal reef flats lie as much as $7 \mathrm{~m}$ above mean ocean level due to a combination of year-round ocean swell, wave-set up and lagoonal ponding (yes I was shocked too by the magnitude). This is also the case on reef-flat terraces in areas with macro-tidal ranges, where corals can grow above mean sea level and survive exposure during daily low tides. This makes coral depth ranges in Table 2 somewhat debatable given that none show the possibility 
of growth above low tide level.

This important point that has been largely ignored by those who claim a mid-Holocene highstand based on reef terrace data.

Second, on line 290 it is claimed that in contrast to individual coral species, which have large depth ranges, "...Accurate palaeo-water depth intervals can be usually defined based on coral assemblages..." I think you mean 'more precise' depth intervals can be defined from coral assemblages. This claim is also problematic given that it requires that corals be identified to species level, and that the species concept in Scleractinia is debatable due to hybridization in space and time (see Veron's '95 book on the subject). So individual coral depth ranges and coral assemblages defined from modern reefs are unlikely to be applicable to fossil reefs from the LIG.

The truth is that only by combining coralgal assemblages with facies analysis can you precisely and accurately determine SL from fossil reefs. And that requires determining the facies sequence in modern reefs which has been largely ignored due to the difficulty of drilling in zones with high wave energy. You might argue that facies sequences are subject to the same caveat, but facies are controlled by both physical and ecological interactions and are therefore better conserved in time than coral biology. An additional difficulty in comparing modern vs fossil coral assemblages is the problem of taphonomic bias identified from the comparison of life and death assemblages. It is common that fossil assemblages have significant differences in the proportions of branching and fragile corals which are commonly removed by tropical cyclones. Again such problems could be avoided by comparing sub-surface facies on modern reefs, rather than their surface assemblages.

Finally a comment on the interpretation of the data set from the Huon Peninsula. As I state in my 2011 review: "...It is clear ... that the interpretation of LIG reef architecture in the Huon Peninsula has been obfuscated by various attempts to obtain a terrace chronology. The fundamental problem has been that unreliable U-series age determi-

Interactive comment

\section{C2}

Printer-friendly version

Discussion paper 
nations, which clearly fail any test of stratigraphic consistency, have driven the analysis of the stratigraphy itself, rather than the other way round. This has led to disconformities ESSDD being inferred between stratigraphically inverted ages, or inverted ages simply being ignored, rather than acknowledging that many dates have large true-age variabilities and that more than $50 \%$ of those with "reliable" isotopic signatures have discordant 231 Pa ages (Scholz and Mangini, 2007). As a result, SL histories determined from these inadequate data are premature, especially interpretations of extreme excursions based on ages alone (Esat et al., 1999)."

In summary, these additional uncertainties should be added to the discussion at the end of the paper.

Interactive comment on Earth Syst. Sci. Data Discuss., https://doi.org/10.5194/essd-2020-261, 2020. 